(6)

OPEN ACCESS

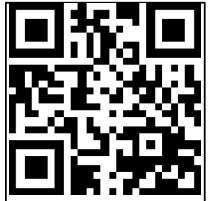

Open Access

scan to access more

free content

Handling editor Tore K Kvien

- Additional material is published online only. To view please visit the journal online (http://dx.doi.org/10.1136/ annrheumdis-2013-204963).

${ }^{1}$ Med. Department 1, Rheumatology, Charité University Medicine Berlin, Berlin, Germany

${ }^{2}$ Rheumazentrum Ruhrgebiet, Herne, Germany

${ }^{3}$ Division of Rheumatology, Department of Medicine, University of Massachusetts Medical School, Worcester, Massachusetts, USA

${ }^{4}$ Research and Development, Sanofi, Bridgewater, New Jersey, USA

${ }^{5}$ Translational Medicine, Regeneron Pharmaceuticals, Inc., Tarrytown, New York, USA

${ }^{6}$ Division of Rheumatology, Toronto Hospital Western Division, Toronto, Canada

\section{Correspondence to}

Dr Joachim Sieper, Professor of Rheumatology, Charité Medical School, Department of Medicine 1, Campus Benjamin Franklin, Hindenburgdamm 30, Berlin 12200, Germany; joachim.sieper@charite.de

Received 22 November 2013 Revised 22 January 2014 Accepted 24 January 2014 Published Online First 18 February 2014

\title{
Sarilumab for the treatment of ankylosing spondylitis: results of a Phase II, randomised, double-blind, placebo-controlled study (ALIGN)
}

\author{
Joachim Sieper, ${ }_{1}^{1}$ Jürgen Braun, ${ }^{2}$ Jonathan Kay, ${ }^{3}$ Salvatore Badalamenti, ${ }^{4}$ \\ Allen R Radin, ${ }^{5}$ Lixia Jiao, ${ }^{4}$ Stefano Fiore, ${ }^{4}$ Tanya Momtahen, ${ }^{4}$ \\ George D Yancopoulos, ${ }^{5}$ Neil Stahl, ${ }^{5}$ Robert D Inman ${ }^{6}$
}

\section{ABSTRACT}

Objectives The ALIGN study (NCT01061723)

evaluated the efficacy and safety of sarilumab, the first fully human monoclonal antibody against interleukin-6 receptor- $\alpha$ (IL-6R $\alpha)$, in patients with ankylosing spondylitis (AS).

Methods Patients with active AS despite conventional treatment were randomised to placebo, or one of five subcutaneous dose regimens of sarilumab $(100,150$ or $200 \mathrm{mg}$ every other week, or 100 or $150 \mathrm{mg}$ every week), for 12 weeks. The primary efficacy end point was the percentage of patients achieving the Axial SpondyloArthritis international Society (ASAS) 20 response criteria at week 12 . Secondary endpoints included ASAS40 response, ASAS partial remission, AS Disease Activity Score, high-sensitivity C-reactive protein (hs-CRP) value, and safety.

Results Baseline demographic and disease characteristics of the 301 patients enrolled were similar across treatment groups. At week 12, there was no statistically significant difference in ASAS20 response rate between placebo (ASAS20 $=24.0 \%$ ) and any sarilumab dose group. A significantly greater reduction in hs-CRP value was achieved with the higher sarilumab doses versus placebo. No other statistically significant differences were evident for secondary efficacy endpoints.

The most common treatment-emergent adverse events reported for sarilumab included infections (non-serious), neutropenia, and increase in alanine aminotransferase. No cases of tuberculosis, opportunistic, or fungal infections, or bowel perforations were reported. Seven patients experienced a treatment-emergent serious adverse event (all in sarilumab treatment groups). No deaths occurred.

Conclusions The ALIGN study shows that IL-6R $\alpha$ blockade with sarilumab was not an effective treatment for AS. Sarilumab was generally well tolerated with a manageable safety profile.

\section{INTRODUCTION}

Ankylosing spondylitis (AS) is a chronic inflammatory disease that typically develops in the third decade of life, ${ }^{1-3}$ affecting men about twice as frequently as women. ${ }^{3}$ A close relationship exists between the prevalence of the HLA-B27 gene and the development of AS, with $80-95 \%$ of patients with AS being HLA-B27 positive. ${ }^{4}$ Traditional therapies, such as non-steroidal anti-inflammatory drugs (NSAIDs), have limited efficacy in many patients. Although biologic agents have significantly improved outcomes, $30-40 \%$ of patients experience substantial disease activity despite anti-tumour necrosis factor (TNF)- $\alpha$ therapy ${ }^{5-7}$ For some patients, the initial response to anti-TNF- $\alpha$ agents diminishes over time and they are switched to another anti-TNF agent. ${ }^{8}$ However, if TNF-blockade fails to control AS disease activity, no other treatment options are currently available. Because high levels of TNF- $\alpha$ and interleukin (IL)- 6 have been found in biopsy specimens from sacroiliac joints of patients with AS, these cytokines were thought to at least partially mediate the inflammation in AS. ${ }^{9-12}$ Circulating levels of IL-6 also correlate with spinal inflammation, ${ }^{13}$ and the clinical and radiological efficacy of TNF-blockade in AS is associated with significant reduction of IL-6 and C-reactive protein (CRP) levels. ${ }^{14}$ Thus, blockade of IL-6 is an appealing potential therapeutic option.

Tocilizumab (TCZ) is a humanised monoclonal antibody against IL-6 receptor- $\alpha$ (IL-6R $\alpha$ ), and is approved for the treatment of rheumatoid arthritis (RA). ${ }^{15}$ When the current study was designed and initiated, case reports suggested benefit with TCZ in AS patients who had been refractory to two or more anti-TNF agents. ${ }^{16-19}$ After the study had been completed, negative results of a placebocontrolled trial of tocilizumab in patients with active AS were reported. ${ }^{20}$ No anti-IL-6 agent is currently approved for the treatment of AS.

Sarilumab, the first fully human monoclonal antibody directed against IL-6R $\alpha$, is currently in development for RA. The phase II ALIGN study reported here evaluated the efficacy and safety of five subcutaneously (SC) administered sarilumab dose regimens versus placebo in anti-TNF-naive patients with active AS despite treatment with NSAIDs.

\section{METHODS}

\section{Study design}

ALIGN was a randomised, multicentre, doubleblind, parallel-group, placebo-controlled study conducted in 68 study centres in Europe, Canada and the USA (NCT01061723). The study duration was 22 weeks, including 4 weeks of screening, 12 weeks of treatment and 6 weeks of post-treatment follow-up. Patients were randomised with balanced allocation to receive either SC placebo or sarilumab 
(100, 150 or $200 \mathrm{mg}$ every other week (q2w), or 100 or $150 \mathrm{mg}$ every week (qw), with q2w dosing alternating with placebo) for 12 weeks. Patients were stratified according to levels of high-sensitivity (hs)-CRP $(\leq 1.5 \mathrm{mg} / \mathrm{dL}$ or $>1.5 \mathrm{mg} / \mathrm{dL})$ at screening and region (Western countries vs non-Western countries). Patients who completed the 12 -week treatment period were offered enrolment in a long-term extension study, NCT01118728. Patients who chose not to enrol in the extension study had a post-treatment safety follow-up visit 6 weeks after the end-of-treatment visit. Further details regarding scheduling of clinic visits are provided in online supplemental materials.

This study was performed in compliance with Good Clinical Practice. The appropriate institutional review boards/ethics committees approved the study, and written informed consent was obtained from each patient before study participation.

\section{Patients}

Consecutively enrolled patients were randomised using a central randomisation scheme generated by an Interactive Voice Response System. All data were collected during scheduled clinic and home visits. Patients included in the study were men and women between the ages of 18 and 75 years, had had active AS for at least 3 months, and Bath AS Disease Activity Index (BASDAI) ${ }^{21}$ and total back pain score $\geq 4$ at screening and baseline, without complete fusion of the spine, and did not respond adequately to, or were intolerant of, $\geq 2$ NSAIDs (each taken for $\geq 2$ weeks). Patients treated with oral prednisone or equivalent corticosteroids ( $\leq 10 \mathrm{mg} /$ day) must have been taking a stable dose for $\geq 2$ weeks prior to baseline. Patients treated with the disease-modifying anti-rheumatic drugs hydroxychloroquine ( $\leq 400 \mathrm{mg} /$ day), sulfasalazine ( $\leq 3 \mathrm{~g} /$ day) or methotrexate (MTX) $(\leq 25 \mathrm{mg} /$ week) must have been on a stable dose $\geq 12$ weeks prior to baseline.
Patients were excluded from the study if they had a past history of non-response to any anti-TNF- $\alpha$ agent or non-response to any other biological treatment for AS, had received treatment with a disease modifying anti-rheumatic drug (DMARD) (except those allowed in the inclusion criteria) or any biological agent within 3 months prior to screening, had received oral prednisone or equivalent corticosteroids $>10 \mathrm{mg} /$ day within 6 weeks prior to screening, intramuscular or intra-articular corticosteroids within 4 weeks of screening, or had previously been treated with cyclosporine or azathioprine.

\section{Study objectives and efficacy endpoints}

The primary study objectives were to evaluate sarilumab efficacy during the 12-week treatment period according to the Axial SpondyloArthritis international Society (ASAS) $20^{22}$ outcome measure in patients with AS, and to define the best dose/dosage regimen for further development.

The primary efficacy endpoint was the percentage of patients who achieved the ASAS20 response criteria at week 12. This was defined as an improvement of at least $20 \%$ and an absolute improvement of at least one unit relative to baseline on a $0-10$ numerical rating scale (NRS) in at least three of the following four ASAS improvement criteria (ASAC-IC) domains: physical function (Bath AS Function Index (BASFI)), ${ }^{23}$ total back pain, patient global assessment and inflammation (mean of intensity and duration of morning stiffness components from the BASDAI); and no worsening $\geq 20 \%$ and $\geq 1$ unit relative to baseline on a scale of $0-10$ NRS in the remaining fourth domain.

Secondary efficacy end points at week 12 included the percentage of patients who achieved: ASAS40 response (as for ASAS20, with improvement $\geq 40 \%$ and absolute improvement $\geq 2$ units), ASAS partial remission (value of $\leq 2$ units on a $0-10$ NRS in each of the four ASAS-IC domains), ASAS5/6 response (composite score of six domains ie, ASAS-IC, spinal mobility

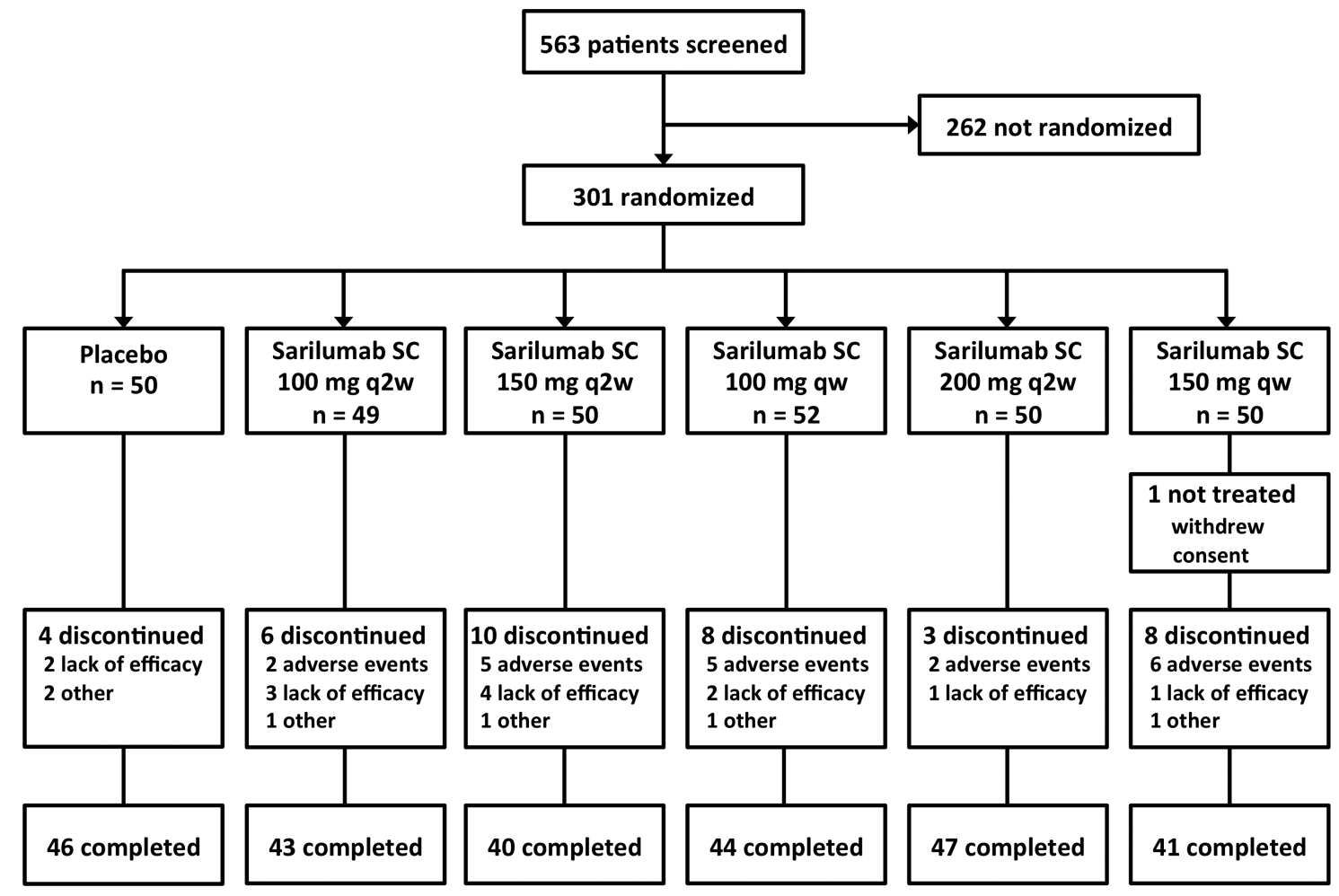

Figure 1 Patient disposition. SC, subcutaneous; q2w, every 2 weeks; qw, every week. 
and hs-CRP, response being 20\% improvement in five domains without deterioration in the sixth), and change from baseline in: ASAS individual components, MRI score of the spine (AS spine MRI-active scoring system, ASspiMRI-a), AS Disease Activity Score (ASDAS) score, BASDAI score, Bath AS Metrology Index (BASMI, 11-point scale), hs-CRP value and chest expansion.

The incidences of swollen and tender joints were not captured, and the impact of sarilumab on peripheral disease was not assessed.

\section{Sample size calculation}

On the basis of previous trials with biologics in AS, it was assumed that the response rates would be $25 \%$ in the placebo group and $60 \%$ in at least one of the active treatment groups. With 50 patients per group, the study had $\sim 80 \%$ power to detect a difference of 35 percentage points between any dose of sarilumab and placebo using a two-sided test with $\alpha=0.01$ due to the application of Hommel's procedure to adjust for multiplicity.

\section{Statistical analyses}

Primary efficacy analysis

The primary efficacy end point, ASAS20 response at week 12, was assessed to demonstrate that at least one sarilumab dose differed from placebo. Comparisons made between each sarilumab dose group and the placebo group were adjusted for multiplicity using Hommel's procedure. ASAS20 response at week 12 was analysed using the two-sided Cochran-Mantel-Haenszel test stratified by screening hs-CRP and region. Pairwise comparisons of response rates and 95\% CIs for ORs between each sarilumab dose and placebo were derived by testing each active dose group versus placebo separately. The Mantel-Haenszel estimate of the OR and the corresponding 95\% CIs were derived the same way.

A last-observation-carried-forward procedure was used to impute any missing ASAS20 components for patients who missed at least one ASAS component at week 12 for any reason. Patients who discontinued study treatment due to lack of efficacy before week 12 were considered as non-responders. Treatment-by-subgroup interactions were also analysed for ASAS20 response.

\section{Secondary efficacy analyses}

Binary secondary efficacy end points, for example, ASAS40 response, ASAS partial remission and ASAS5/6 response at week 12 were analysed as defined above for the primary efficacy end point.

Table 1 Patient demographics and baseline characteristics—randomised population

\begin{tabular}{|c|c|c|c|c|c|c|c|}
\hline & \multirow[b]{2}{*}{$\begin{array}{l}\text { Placebo } \\
(n=50)\end{array}$} & \multicolumn{6}{|c|}{ Sarilumab } \\
\hline & & $\begin{array}{l}100 \mathrm{mg} \mathrm{q2w} \\
(\mathrm{n}=49)\end{array}$ & $\begin{array}{l}150 \mathrm{mg} \mathrm{q} 2 \mathrm{w} \\
(\mathrm{n}=50)\end{array}$ & $\begin{array}{l}100 \mathrm{mg} \mathrm{qw} \\
(\mathrm{n}=52)\end{array}$ & $\begin{array}{l}200 \mathrm{mg} \mathrm{q} 2 \mathrm{w} \\
(\mathrm{n}=50)\end{array}$ & $\begin{array}{l}150 \mathrm{mg} \mathrm{qw} \\
(\mathrm{n}=50)\end{array}$ & $\begin{array}{l}\text { All } \\
(n=301)\end{array}$ \\
\hline \multicolumn{8}{|l|}{ Demographics } \\
\hline Age, years, mean (SD) & $40.3(11.7)$ & $42.4(10.8)$ & $43.0(11.3)$ & $40.4(11.5)$ & $37.2(10.4)$ & 41.1 (11.1) & $40.7(11.2)$ \\
\hline Male, n (\%) & $38(76.0)$ & $30(61.2)$ & $34(68.0)$ & $37(71.2)$ & $40(80.0)$ & $39(78.0)$ & $218(72.4)$ \\
\hline Caucasian/white, n (\%) & $49(98.0)$ & $49(100)$ & $48(96.0)$ & 49 (94.2) & $48(96.0)$ & $49(98.0)$ & $292(97.0)$ \\
\hline BMI $\left(\mathrm{kg} / \mathrm{m}^{2}\right)$, mean (SD) & $26.97(5.30)$ & $26.12(4.83)$ & $25.43(3.93)$ & $27.31(4.61)$ & $27.10(5.24)$ & $26.88(4.21)$ & $26.64(4.72)$ \\
\hline \multicolumn{8}{|l|}{ Region, n (\%) } \\
\hline Western countries* & $39(78.0)$ & 39 (79.6) & $40(80.0)$ & $41(78.8)$ & $39(78.0)$ & $40(80.0)$ & $238(79.1)$ \\
\hline RoWt & $11(22.0)$ & $10(20.4)$ & $10(20.0)$ & $11(21.2)$ & $11(22.0)$ & $10(20.0)$ & $63(20.9)$ \\
\hline HLA-B27 positive, \% & 74.0 & 78.7 & 76.0 & 78.8 & 78.0 & 81.6 & 77.9 \\
\hline \multicolumn{8}{|l|}{ Baseline characteristics } \\
\hline $\begin{array}{l}\text { Duration of AS (years } \\
\text { since diagnosis), } \\
\text { mean (SD) }\end{array}$ & $9.45(8.31)$ & $8.50(10.30)$ & $8.55(10.65)$ & $7.13(7.96)$ & $7.13(7.08)$ & $5.55(5.31)$ & $7.71(8.48)$ \\
\hline \multicolumn{8}{|l|}{ Screening hs-CRP level, n (\%) } \\
\hline$\leq 1.5 \mathrm{mg} / \mathrm{dL}$ & $28(56.0 \%)$ & $27(55.1 \%)$ & $27(54.0 \%)$ & $29(55.8 \%)$ & $28(56.0 \%)$ & $27(54.0 \%)$ & $166(55.1 \%)$ \\
\hline \multicolumn{8}{|l|}{ Number of prior DMARDs, $\mathrm{n}(\%)$} \\
\hline None & $41(82.0)$ & $41(83.7)$ & $39(78.0)$ & $39(75.0)$ & $40(80.0)$ & $44(88.0)$ & $244(81.1 \%)$ \\
\hline 1 & $8(16.0)$ & $8(16.3)$ & $11(22.0)$ & $13(25.0)$ & $10(20.0)$ & $6(12.0)$ & $56(18.6 \%)$ \\
\hline 2 & $1(2.0)$ & 0 & 0 & 0 & 0 & 0 & $1(0.3 \%)$ \\
\hline History of smoking $n(\%)$ & $27(54.0)$ & $30(61.2)$ & $21(42.0)$ & $27(51.9)$ & $28(56.0)$ & $31(62.0)$ & $164(54.5 \%)$ \\
\hline Alcohol use, n (\%) & $33(66.0)$ & $36(73.5)$ & $33(66.0)$ & $33(63.5)$ & $32(64.0)$ & $36(72.0)$ & $203(67.4 \%)$ \\
\hline \multicolumn{8}{|c|}{ ASAS individual core components ( $0-10$ scale) } \\
\hline Back pain, mean (SD) & $6.62(2.14)$ & $6.73(1.88)$ & $6.60(1.57)$ & $6.91(1.70)$ & $6.90(1.66)$ & $6.52(1.63)$ & $6.72(1.76)$ \\
\hline Physical function, mean (SD) & $4.44(1.63)$ & $4.24(1.58)$ & $4.05(1.45)$ & $4.25(1.66)$ & $3.99(1.68)$ & $3.95(1.62)$ & $4.15(1.60)$ \\
\hline $\begin{array}{l}\text { Patient global assessment, } \\
\text { mean (SD) }\end{array}$ & $6.88(1.97)$ & $6.82(1.88)$ & $6.44(1.75)$ & $6.94(1.70)$ & $6.78(1.67)$ & $6.48(1.62)$ & $6.72(1.76)$ \\
\hline Inflammation, mean (SD) & $6.91(2.12)$ & $6.21(1.73)$ & $6.55(1.56)$ & $6.49(1.96)$ & $7.05(1.82)$ & $6.26(1.88)$ & $6.58(1.87)$ \\
\hline \multicolumn{8}{|l|}{ MRI (ASspiMRI) total score } \\
\hline Number & 49 & 48 & 50 & 52 & 49 & 50 & 298 \\
\hline Mean (SD) & $8.8(8.8)$ & $6.8(7.6)$ & $7.8(11.1)$ & $9.1(11.0)$ & $9.2(10.2)$ & $9.7(9.7)$ & $8.6(9.8)$ \\
\hline
\end{tabular}


An analysis of covariance model, including terms for baseline, treatment, screening hs-CRP level and region, was used to assess treatment differences in change from baseline for continuous efficacy variables. Descriptive statistics including number of subjects, mean, median, minimum and maximum were provided. Additionally, difference in least-square means, the corresponding $95 \%$ CIs and the $\mathrm{p}$ values were provided for comparisons of each sarilumab dose versus placebo.

Active inflammation in the spine visible on MRI short tau inversion recovery sequence was analysed by applying the MRI score for ASspiMRI-a, as has been described before. ${ }^{24}$

\section{Safety analysis}

Safety summaries were descriptive and no hypothesis testing was conducted. Summary of treatment-emergent adverse events (TEAEs) was based on Medical Dictionary for Regulatory Activities coding of verbatim terms reported by investigators. TEAEs were defined as any AEs that newly developed or worsened, or became serious on or after the day of first dose intake of study drug, up to the day of end of study. The incidences of abnormal laboratory values, vital signs and ECG parameters were recorded.

\section{RESULTS}

\section{Patients}

Overall, 301 patients comprised the intention-to-treat (ITT) population and were randomised to treatment between 4 February 2010 and 21 June 2011 (figure 1). One patient (150 mg qw group) withdrew informed consent prior to the first scheduled treatment and is included in ITT efficacy analyses and excluded from safety analyses. Thirty-nine patients discontinued study treatment before week 12. AEs or lack of efficacy were the most common reasons for treatment discontinuation; other reasons included withdrawal of consent (three patients), randomisation by mistake (two patients) and lost-to-follow-up (one patient). There were no deaths.

\section{Demographics, baseline and treatment characteristics}

Baseline demographic and disease characteristics were similar across all treatment groups (table 1). The majority of patients had the HLA-B27 antigen.

\section{Primary efficacy}

At week 12, there was no statistically significant difference in ASAS20 response between placebo (24.0\%) and any of the sarilumab doses $(24.5,30.0,19.2,30.0$ and $38.0 \%$, respectively for $100 \mathrm{mg} \mathrm{q} 2 \mathrm{w}, 150 \mathrm{mg} \mathrm{q} 2 \mathrm{w}, 100 \mathrm{mg} \mathrm{qw}, 200 \mathrm{mg} \mathrm{q} 2 \mathrm{w}$ and $150 \mathrm{mg} \mathrm{qw}$ ) (figure 2A). The response was greatest in the highest dose regimen tested, $150 \mathrm{mg}$ qw (38.0\%), but was not statistically significant versus placebo (nominal and adjusted $\mathrm{p}$ values $>0.05$ vs placebo).

A treatment interaction was observed based on screening hs-CRP value with evidence of a significant ASAS20 treatment response among patients with hs-CRP $>1.5 \mathrm{mg} / \mathrm{dL}(\mathrm{p}=0.0493)$. However, this effect appears to be limited to one dose group only (150 mg qw) (figure 2B). Other subgroup interaction analyses for ASAS20 were not significantly different, including gender (men vs women, $\mathrm{p}=0.8571$ ), race (Caucasian vs all other races, $\mathrm{p}=0.9998$ ), past history of anti-TNFs (yes vs no, $\mathrm{p}=0.8373$ ), region (Western countries vs non-Western countries) $(\mathrm{p}=0.9082)$, number of prior DMARDs (none, 1, 2, $\geq 3, p=0.2342$ ) and smoking history (yes vs no, $\mathrm{p}=0.7207$ ).

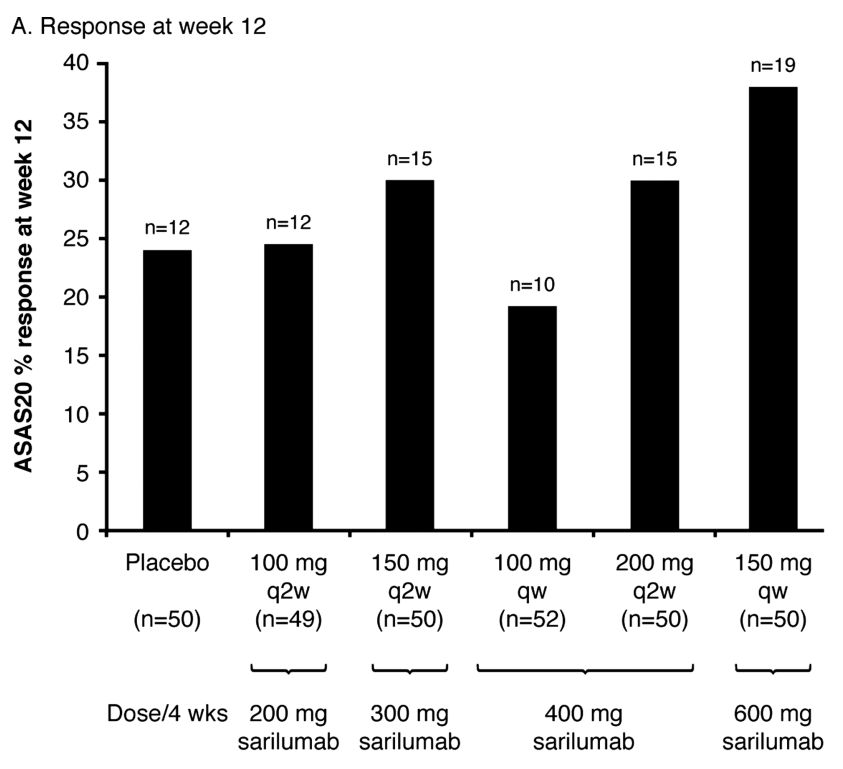

B. Response at week 12 by CRP level

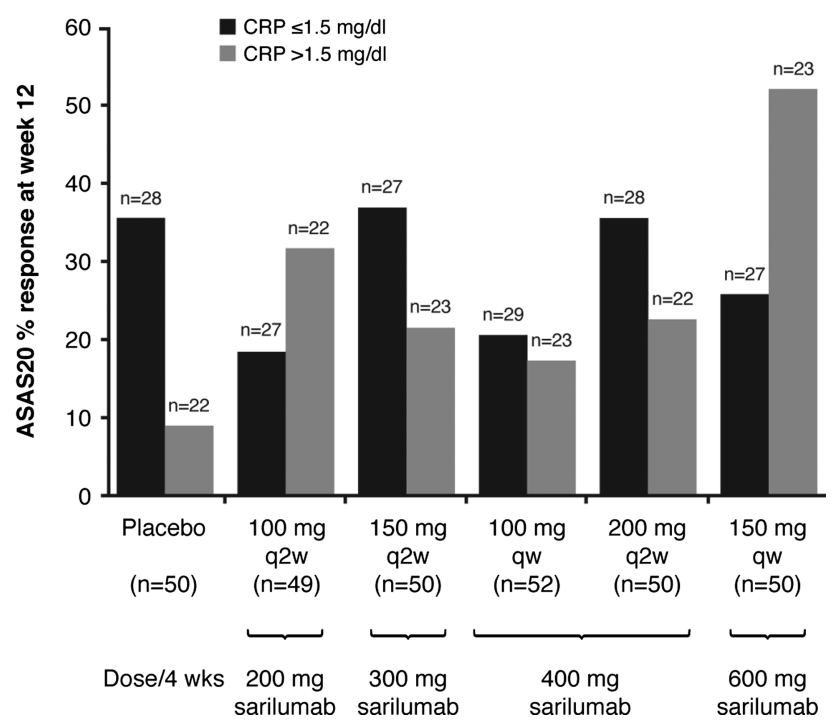

Figure 2 Incidence of ASAS20 response - ITT population. Percentage response calculated using the number of ITT patients in the corresponding treatment group within each subgroup as denominator. At week 12, p>0.05 (nominal and adjusted) for all sarilumab-treated groups vs placebo. CRP, high sensitivity C-reactive protein; ITT, intent-to-treat.

\section{Secondary efficacy}

Secondary efficacy end points at week 12 showed that the rates of ASAS40 response, ASAS partial remission, and ASAS5/6 response were generally not significantly different from placebo. Only the ASAS5/6 response rate in the $150 \mathrm{mg}$ qw group $(n=16,32.0 \%)$ showed a significant difference versus placebo $(n=3,6.0 \%$ : $\mathrm{p}=0.001$; OR 6.4 (CI 1.8 to 22.8)) (table 2). In regard to the four individual ASAS core components (back pain, physical function, patient global assessment and inflammation) at week 12, only back pain in the $150 \mathrm{mg}$ qw dose group showed a statistically significantly higher treatment effect (change from baseline) compared to placebo: mean (SD) change $-1.6(2.1)$ vs $-0.8(1.8), \mathrm{p}=0.0344$. A significantly higher treatment effect was seen at the higher sarilumab doses compared to placebo for ASDAS score mean (SD) change $-0.4(0.7),-0.8(1.2),-1.1(0.8),-1.2(0.9)$, and -1.6 
Table 2 Secondary efficacy endpoints at week 12-ITT population

\begin{tabular}{|c|c|c|c|c|c|c|}
\hline & \multirow[b]{2}{*}{$\begin{array}{l}\text { Placebo } \\
(n=50)\end{array}$} & \multicolumn{5}{|c|}{ Sarilumab } \\
\hline & & $\begin{array}{l}100 \mathrm{mg} \mathrm{q} 2 \mathrm{w} \\
(\mathrm{n}=49)\end{array}$ & $\begin{array}{l}150 \mathrm{mg} \text { q2w } \\
(\mathrm{n}=50)\end{array}$ & $\begin{array}{l}100 \mathrm{mg} q w \\
(n=52)\end{array}$ & $\begin{array}{l}200 \mathrm{mg} \mathrm{q} 2 \mathrm{w} \\
(\mathrm{n}=50)\end{array}$ & $\begin{array}{l}150 \mathrm{mg} q w \\
(\mathrm{n}=50)\end{array}$ \\
\hline \multicolumn{7}{|c|}{ Incidence of key secondary efficacy endpoint-responders } \\
\hline ASAS40, n (\%) & $4(8.0)$ & $7(14.3)$ & $8(16.0)$ & $3(5.8)$ & $9(18.0)$ & $10(20.0)$ \\
\hline ASAS partial remission, $\mathrm{n}(\%)$ & $1(2.0)$ & $4(8.2)$ & $1(2.0)$ & $1(1.9)$ & $1(2.0)$ & $4(8.0)$ \\
\hline ASAS5/6 response, $n(\%)$ & $3(6.0)$ & $6(12.2)$ & $5(10.0)$ & $7(13.5)$ & $7(14.0)$ & $16(32.0)^{*}$ \\
\hline \multicolumn{7}{|c|}{ Change from baseline in key secondary efficacy components } \\
\hline \multicolumn{7}{|c|}{ ASAS individual core component change, mean (SD) (0-10 scale) } \\
\hline Back pain & $-0.8(1.8)$ & $-1.3(2.2)$ & $-1.2(2.4)$ & $-0.5(1.8)$ & $-0.9(2.2)$ & $-1.6(2.1)$ \\
\hline Physical function & $-0.6(1.2)$ & $-0.5(1.7)$ & $-0.4(2.0)$ & $-0.1(1.4)$ & $-0.6(1.9)$ & $-1.1(1.9)$ \\
\hline Patient global assessment & $-1.0(1.9)$ & $-1.1(2.3)$ & $-0.8(2.3)$ & $-0.4(2.2)$ & $-0.9(2.2)$ & $-1.6(2.0)$ \\
\hline Inflammation & $-1.4(1.8)$ & $-0.8(2.0)$ & $-1.1(2.0)$ & $-0.7(2.1)$ & $-1.0(1.9)$ & $-1.8(2.3)$ \\
\hline ASspiMRI total score change, mean (SD) & $-0.5(2.2)$ & $-0.5(1.8)$ & $-0.1(3.4)$ & $0.1(2.4)$ & $-0.3(3.3)$ & $0.3(3.3)$ \\
\hline ASDAS score change, mean (SD) & $-0.4(0.7)$ & $-0.5(0.9)$ & $-0.8(1.2)$ & $-1.1(0.8)$ & $-1.2(0.9)$ & $-1.6(0.9)$ \\
\hline BASDAI score change, mean (SD) & $-0.9(1.7)$ & $-0.8(1.9)$ & $-1.1(2.0)$ & $-0.4(1.4)$ & $-0.9(1.8)$ & $-1.2(1.8)$ \\
\hline BASMI score change, mean (SD) & $-0.2(0.8)$ & $-0.2(0.9)$ & $-0.2(0.8)$ & $-0.4(0.9)$ & $-0.1(0.8)$ & $-0.2(0.7)$ \\
\hline hs-CRP (mg/dl) change, mean (SD) & $-3.7(19.1)$ & $-1.2(17.9)$ & $-5.8(27.6)$ & $-13.5(20.3)^{* *}$ & $-11.5(17.5)^{* * *}$ & $-14.3(15.3)^{* * *}$ \\
\hline Chest expansion $(\mathrm{cm})$ change, mean (SD) & $0.2(1.0)$ & $0.2(1.2)$ & $0.0(1.2)$ & $-0.1(0.9)$ & $0.1(1.3)$ & $0.3(1.3)$ \\
\hline
\end{tabular}

(0.9) respectively for placebo, $150 \mathrm{mg} \mathrm{q} 2 \mathrm{w}, 100 \mathrm{mg} \mathrm{qw}$, $200 \mathrm{mg} \mathrm{q} 2 \mathrm{w}$ and $150 \mathrm{mg} \mathrm{qw} ; \mathrm{p}=0.0112$ for $150 \mathrm{mg} \mathrm{q} 2 \mathrm{w}$ and $\mathrm{p}<0.0001$ for each of the other three doses versus placebo.

Sarilumab at doses greater than $150 \mathrm{mg} \mathrm{q} 2 \mathrm{w}$ significantly reduced hs-CRP values compared to placebo; mean (SD) $\mathrm{mg} / \mathrm{dL}$ change that is, placebo -3.7 (19.1), $100 \mathrm{mg} \mathrm{q} 2 \mathrm{w}-1.2$ (17.9, not significant (ns)), $150 \mathrm{mg} \mathrm{q} 2 \mathrm{w}-5.8$ (27.6, ns), $100 \mathrm{mg} \mathrm{qw}$ -13.5 (20.3, p=0.0007), $200 \mathrm{mg} \mathrm{q} 2 \mathrm{w}-11.5$ (17.5, $\mathrm{p}<0.0001)$, and $150 \mathrm{mg} \mathrm{qw}-14.3(15.3, \mathrm{p}<0.0001)$.

Changes from baseline for BASDAI and BASMI scores and chest expansion, were not statistically different from placebo at all sarilumab doses tested. Only small changes were observed for the MRI spine score in all groups (table 2), which did not differ significantly between the placebo-treated and sarilumab-treated groups. Correlation coefficients between change from baseline in MRI score and change from baseline in hs-CRP value at week 12 were 0.04 for the placebo group and ranged from -0.03 to 0.19 for the sarilumab groups ( $\mathrm{p}=\mathrm{ns}$ for all groups).

\section{Safety}

Mean treatment duration (76.2-81.4 days), treatment exposure (10.5-11.0 patient-years) and overall treatment compliance (94-100\%) were comparable across all treatment groups. The proportion of patients who experienced at least one TEAE was $\sim$ twofold higher in the sarilumab groups (64\%-78\%, and with no clear dose response relationship), compared with $36 \%$ in the placebo group (see online supplemental table 1). Infections and infestations, particularly upper respiratory tract infections, were the most common TEAE reported by all groups. Twelve cases of accidental overdose (defined as administration of at least twice the treatment dose during fewer than 6 days) were reported; all cases were asymptomatic.

Overall, 20 patients on sarilumab experienced a TEAE that led to treatment discontinuation, the most frequent being neutropenia $(n=6)$, gastrointestinal disorders $(n=5)$ and increased alanine aminotransferase (ALT) $(n=4)$. All events leading to discontinuation resolved following treatment cessation with the exception of Crohn's disease $(n=1$; diagnosis reported in a patient with a previous history of colitis and anterior uveitis). Serious TEAEs were infrequent (seven patients). All reported events occurred in the sarilumab groups; of these, five events (one per patient) resulted in treatment discontinuation (neutropenia, ALT increase, helicobacter gastritis, false positive tuberculosis test and epileptic seizure) (further details are provided in the online supplemental table 2). No severe or serious infections were associated with grade $3\left(\geq 500-1000 / \mathrm{mm}^{3}\right)$ or grade $4\left(<500 / \mathrm{mm}^{3}\right)$ neutropenia, and no deaths were reported.

Sarilumab was associated with neutropenia and elevations in ALT ( $>3 \times$ upper limit of normal), total cholesterol and lowdensity lipoprotein. Generally, changes in other laboratory tests, vital signs and ECG parameters were not considered clinically significant.

\section{DISCUSSION}

The ALIGN study showed that SC-administered sarilumab was generally well tolerated but did not demonstrate a statistically or clinically significant effect compared to placebo in patients with active AS who had an inadequate response to, or were intolerant of, NSAIDs. A statistically significant reduction in hs-CRP following SC sarilumab treatment demonstrated that a biological effect of IL-6 blockade was achieved. However, lack of associated clinical or imaging improvement that is, similar reductions in functional and clinical parameters as measured by MRI, BASDAI, BASMI and BASFI scores in placebo-treated and sarilumab-treated patients, further suggests that IL-6 may not play a major role in the inflammatory process underlying AS. The significant reduction observed in the ASDAS score with sarilumab likely reflects inclusion of hs-CRP in this composite measure, suggesting that ASDAS may not be a robust outcome parameter when changes in CRP values could be dissociated 
from changes in disease activity, as with anti-IL-6 therapies. Variability in the observed efficacy of sarilumab among individual treatment groups in the ALIGN study most likely reflects the inclusion of only 49-52 subjects in each individual treatment group, since no sarilumab dose group yielded a statistically significantly greater proportion of ASAS20 responders when compared to the placebo group (figure $2 \mathrm{~A}, \mathrm{p}>0.05$ for all groups). Variability of ASAS20 response at week 12 by hs-CRP stratification among sarilumab groups (figure $2 \mathrm{~B}$ ) potentially supports this assertion.

There was no relationship between changes in hs-CRP and changes in the MRI scores, suggesting that the drug did not have an effect on AS disease-specific inflammation.

Although case reports of treatment with TCZ have suggested benefit of IL-6R $\alpha$ blockade in AS, ${ }^{16-19}$ a recent 12 -week phase II multicentre, randomised, double-blind, placebo-controlled study of TCZ in AS patients did not confirm this. That study used the same primary efficacy end point as the ALIGN study to compare intravenous TCZ $8 \mathrm{mg} / \mathrm{kg}$ versus placebo in $102 \mathrm{AS}$ patients (TCZ, $n=51$; placebo, $n=51$ ). Similar to sarilumab, TCZ also failed to reach its primary efficacy end point despite reducing hs-CRP and ASDAS scores. ${ }^{20}$ These results caution that positive case reports or evidence for a certain pharmacological intervention based on preclinical data, may not always predict the clinical efficacy of a targeted drug in complex diseases of unknown aetiology such as AS. Anti-IL-6R $\alpha$ therapies have shown efficacy in RA. ${ }^{15} 25{ }^{26}$ Sarilumab was studied in the treatment of RA in the phase II/III MOBILITY study (NCT01061736) using the same five doses as in the current trial. Part A of this study demonstrated efficacy of sarilumab in addition to MTX in patients with active, moderate-to-severe RA who had inadequate response to MTX. ${ }^{27}$ Several other drugs with proven efficacy in RA, including sulfasalazine, leflunomide, MTX, anakinra, rituximab and abatacept, have been investigated for the treatment of AS and, thus far, none has shown any clear therapeutic efficacy. ${ }^{28}$ TNF-blockers appear to be effective across a number of inflammatory rheumatic diseases, including RA and AS, whereas, the efficacy of other targeted therapies may be limited to fewer specific indications. Encouraging data from a small study in AS patients evaluating IL-17 blockade, which has shown clinical efficacy in the treatment of psoriasis $^{29}{ }^{30}$ will require further confirmation. ${ }^{31}$

In the current study in AS patients, sarilumab showed a safety profile similar to reports with other IL-6 inhibitors. Infections and laboratory abnormalities, including neutropenia, elevated transaminases and hyperlipidaemia, were the most commonly observed safety findings.

\section{CONCLUSION}

The ALIGN study did not demonstrate efficacy of sarilumab versus placebo for the treatment of active AS, irrespective of a marked reduction in hs-CRP. Thus, the IL-6 pathway does not appear to play an essential role in AS clinical disease activity and may not be an effective drug target for the disease.

Acknowledgements The authors would like to thank the study participants, staff and co-investigators at participating centres. The contribution of Celine Luscan (Clinical Trial Manager, Sanofi R\&D) is greatly appreciated. Medical writing support was provided by Helen Fosam PhD and Carl V Felton PhD of Prime Medica during the preparation of this paper, supported by Sanofi and Regeneron Pharmaceuticals Inc., Responsibility for opinions, conclusions, and interpretation of data lies with the authors. A full list of ALIGN study investigators is provided in the supplemental materials.

Competing interests The ALIGN study was funded by Sanofi and Regeneron Pharmaceuticals, Inc. Joachim Sieper has received research support from AbbVie,
Janssen, Merck, and Pfizer, and consultancy/speaker bureau fees from AbbVie, Merck, Eli Lilly, Novartis, Pfizer, Roche and Sanofi. Jürgen Braun has received research support from AbbVie, Janssen, Merck Sharp \& Dohme, and Pfizer, and consultancy/speaker bureau fees from AbbVie, Celltrion, Merck Sharp \& Dohme, Novartis, Pfizer, Roche and Sanofi. Jonathan Kay has received research support (provided to University of Massachusetts Medical School) from Abbott Laboratories, Ardea Biosciences, Eli Lilly, Fidia Farmaceutici, SpA, Roche Laboratories, and consultancy fees from AbbVie, AstraZeneca, Bristol-Myers Squibb, Celgene, Crescendo Bioscience, EPIRUS Biopharmaceuticals, Genentech, Hospira, Janssen Biotech, medac pharma, PanGenetics, Pfizer, Roche Laboratories, and Sun Pharmaceutical Industries. Robert D Inman has received consultancy fees from Sanofi-Aventis, Pfizer, Amgen, AbbVie, Janssen, and UCB. Salvatore Badalamenti, Lixia Jiao, Stefano Fiore, and Tanya Momtahen are full-time employees and shareholders of Sanofi. Allen R Radin, George D Yancopoulos, and Neil Stahl are full-time employees and shareholders of Regeneron Pharmaceuticals.

Ethics approval Appropriate institutional review boards/ethics committees approved the study and written informed consent was obtained from each patient before study participation.

Provenance and peer review Not commissioned; externally peer reviewed.

Open Access This is an Open Access article distributed in accordance with the Creative Commons Attribution Non Commercial (CC BY-NC 3.0) license, which permits others to distribute, remix, adapt, build upon this work non-commercially, and license their derivative works on different terms, provided the original work is properly cited and the use is non-commercial. See: http://creativecommons.org/ licenses/by-nc/3.0/

\section{REFERENCES}

1 Braun J, Bollow M, Remlinger $\mathrm{G}$, et al. Prevalence of spondylarthropathies in HLA-B27 positive and negative blood donors. Arthritis Rheum 1998;41:58-67.

2 Sieper J, Rudwaleit M, Khan MA, et al. Concepts and epidemiology of spondyloarthritis. Best Pract Res Clin Rheumatol 2006;20:401-17.

3 Zink A, Braun J, Listing J, et al. Disability and handicap in rheumatoid arthritis and ankylosing spondylitis - results from the German rheumatological database. German Collaborative Arthritis Centers. J Rheumatol 2000;27:613-22.

4 Reveille JD. HLA-B27 and the seronegative spondyloarthropathies. Am J Med Sci 1998;316:239-49.

5 Braun J, Sieper J. Ankylosing spondylitis. Lancet 2007;369:1379-90.

6 Mansour M, Cheema GS, Naguwa SM, et al. Ankylosing spondylitis: a contemporary perspective on diagnosis and treatment. Semin Arthritis Rheum 2007;36:210-23

7 Braun J, Sieper J. Editorial: What is the most important outcome parameter in ankylosing spondylitis. Rheumatology 2008;47:1738-40.

8 Haberhauer G, Strehblow C, Fasching P. Observational study of switching anti-TNF agents in ankylosing spondylitis and psoriatic arthritis vs. rheumatoid arthritis. Wien Med Wochenschr 2010;160:220-4.

9 Rajalingham S, Das S. Antagonizing IL-6 in ankylosing spondylitis: a short review. Inflamm Allergy Drug Targets 2012;11:262-5.

10 Smolen JS, Aletaha D, Koeller $M$, et al. New therapies for treatment of rheumatoid arthritis. Lancet 2007;370:1861-74.

11 Braun J, Bollow M, Neure L, et al. Use of immunohistologic and in situ hybridization techniques in the examination of sacroiliac joint biopsy specimens from patients with ankylosing spondylitis. Arthritis Rheum 1995:38:499-505.

12 Bal A, Unlu E, Bahar G, et al. Comparison of serum IL-1 beta, sIL-2R, IL-6, and TNF-alpha levels with disease activity parameters in ankylosing spondylitis. Clin Rheumatol 2007:26:211-15.

13 Visvanathan S, Wagner C, Marini JC, et al. Inflammatory biomarkers, disease activity and spinal disease measures in patients with ankylosing spondylitis after treatment with infliximab. Ann Rheum Dis 2008;67:511-17.

14 Pedersen SJ, Sørensen IJ, Lambert RG, et al. Radiographic progression is associated with resolution of systemic inflammation in patients with axial spondylarthritis treated with tumor necrosis factor $\alpha$ inhibitors: a study of radiographic progression, inflammation on magnetic resonance imaging, and circulating biomarkers of inflammation, angiogenesis, and cartilage and bone turnover. Arthritis Rheum 2011;63:3789-800

15 Actemra Prescribing Information. 2010. http://www.gene.com/gene/products/ information/actemra/pdf/pi.pdf (accessed July 2012).

16 Henes JC, Horger M, Guenaydin I, et al. Mixed response to tocilizumab for ankylosing spondylitis. Ann Rheum Dis 2010;69:2217-8.

17 Brulhart L, Nissen MJ, Chevallier $\mathrm{P}$, et al. Tocilizumab in a patient with ankylosing spondylitis and Crohn's disease refractory to TNF antagonists. Joint Bone Spine 2010;77:625-6

18 Cohen JD, Ferreira R, Jorgensen C. Ankylosing spondylitis refractory to tumor necrosis factor blockade responds to tocilizumab. J Rheumatol 2011;38:1527

19 Shima Y, Tomita T, Ishii T, et al. Tocilizumab, a humanized anti-interleukin-6 receptor antibody, ameliorated clinical symptoms and MRI findings of a patient with ankylosing spondylitis. Mod Rheumatol 2011;21:436-9. 
20 Sieper J, Porter-Brown B, Thompson L, et al. Assessment of short-term symptomatic efficacy of tocilizumab in ankylosing spondylitis: results of randomised, placebo-controlled trials. Ann Rheum Dis 2014;73:95-100.

21 Garrett S, Jenkinson T, Kennedy LG, et al. A new approach to defining disease status in ankylosing spondylitis: the Bath Ankylosing Spondylitis Disease Activity Index. J Rheumatol 1994;21:2286-91.

22 Anderson JJ, Baron G, van der Heijde D, et al. Ankylosing Spondylitis Assessment Group preliminary definition of short-term improvement in ankylosing spondylitis. Arthritis Rheum 2001;44:1876-86.

23 Calin A, Garrett $S$, Whitelock $H$, et al. A new approach to defining functional ability in ankylosing spondylitis: the development of the Bath Ankylosing Spondylitis Functional Index. J Rheumatol 1994;21:2281-5.

24 Braun J, Baraliakos X, Golder W, et al. Magnetic resonance imaging examinations of the spine in patients with ankylosing spondylitis, before and after successful therapy with infliximab: evaluation of a new scoring system. Arthritis Rheum 2003:48:1126-36.

25 Genovese MC, McKay JD, Nasonov EL, et al. Interleukin-6 receptor inhibition with tocilizumab reduces disease activity in rheumatoid arthritis with inadequate response to disease-modifying antirheumatic drugs: the tocilizumab in combination with traditional disease-modifying antirheumatic drug therapy study. Arthritis Rheum 2008;58:2968-80.
26 Smolen JS, Beaulieu A, Rubbert-Roth A, et al. OPTION Investigators. Effect of interleukin-6 receptor inhibition with tocilizumab in patients with rheumatoid arthritis (OPTION study): a double-blind, placebo-controlled, randomised trial. Lancet 2008:371:987-97.

27 Huizinga TW, Fleischmann RM, Jasson $M$, et al. Sarilumab, a fully human monoclonal antibody against IL-6R $\alpha$ in patients with rheumatoid arthritis and an inadequate response to methotrexate: efficacy and safety results from the randomised SARIL-RA-MOBILITY Part A trial. Ann Rheum Dis 2014;73: $1626-34$.

28 Kiltz U, Heldmann F, Baraliakos X, et al. Treatment of ankylosing spondylitis in patients refractory to TNF-inhibition: are there alternatives? Curr Opin Rheumatol 2012;24:252-60.

29 Miossec P, Kolls JK. Targeting IL-17 and TH17 cells in chronic inflammation. Nat Rev Drug Discov 2012;11:763-76.

30 Busquets-Perez N, Marzo-Ortega H, Emery P. Emerging drugs for axial spondyloarthritis including ankylosing spondylitis. Expert Opin Emerging Drugs 2013;18:71-86.

31 Baeten D, Baraliakos X, Braun J, et al. Anti-interleukin-17A monoclonal antibody secukinumab in treatment of ankylosing spondylitis: a randomised, double-blind placebo-controlled trial. Lancet 2013;382:1705-13. 